\title{
Statistical Learning in Persons with Aphasia: A Critical Review of Literature
}

\author{
Darshan $\mathrm{HS}^{1^{*}}$ and Goswami $S P^{2}$ \\ ${ }^{1}$ Junior Research Fellow, Department of Speech-language Pathology, All India Institute of Speech and \\ Hearing, Mysore, India \\ 2Professor of Speech Pathology, Department of Speech-language Pathology, All India Institute of \\ Speech and Hearing, Mysore, India
}

*Corresponding author: Darshan HS, Junior Research Fellow, Department of Speech Language Pathology, All India Institute of Speech and Hearing, Mysuru, Karnataka, India, Tel: +917204131907

\begin{abstract}
Statistical learning is the process of discovering patterns which are present in the input. Serial Reaction Time Task (SRTT) is commonly used to study statistical learning. Recently, many studies have been conducted in aphasia literature. But it is unclear about the magnitude of learning considering the learning conditions, methodological variations and consolidation of learning in persons with aphasia when compared to neurotypical individuals. This review discusses the learning differences based on certain parameters and also suggest the possible methodological innovations in SRTT to be adopted in aphasia research.
\end{abstract}

\section{Keywords}

Sequence learning, Implicit learning, Serial Reaction Time Task, Stroke

\section{Introduction}

Learning is a process of acquiring skills and knowledge. It is driven by a memory system, as it stores the information which is learnt and retrieves it when needed. Learning and memory systems are interconnected. The learnt knowledge in a stored form in the memory system helps to link with the new knowledge during the learning process [1].

According to Ullman's declarative/procedural model, procedural memory and declarative memory are the two types of memory system. Neural substrates of procedural memory involve frontal/basal ganglia network and declarative memory is represented in temporal lobe structures [2,3]. Extensive research has been car- ried out on memory systems, mainly on declarative (explicit) types of memory systems [4,5]. Recently, studies on procedural (implicit) types of memory systems have been explored in normal and language disordered population, and particularly in aphasia [6-8].

Aphasia is an acquired language disorder resulting from brain damage which involves difficulty in understanding and production of language, reading and writing $[9,10]$. Persons with Aphasia (PWA) might also exhibit muscle weakness and paralysis or muscle incoordination of speech musculature, upper and lower limbs. The symptoms and the severity of the aphasia condition varies with each PWA exhibiting the condition. Few types of Aphasia condition involve lesion in temporal structures, leading to impaired declarative system outputs. The studies have proved the above statement with empirical evidence [11,12]. More research is required to confirm whether procedural or implicit system products are impaired or spared in aphasia population.

Implicit and explicit learning are often assessed using tasks that tap procedural and declarative memory systems. One of the forms of implicit learning is statistical learning [13]. Introduced the term 'implicit statistical learning' to cover both domains. Even though the term was combined, the term implicit learning is a broader one and statistical learning will entail inside it. Few researchers pointed out that statistical learning is synonymous to implicit learning and it is a valid and more reliable form of learning. The term statistical learning will

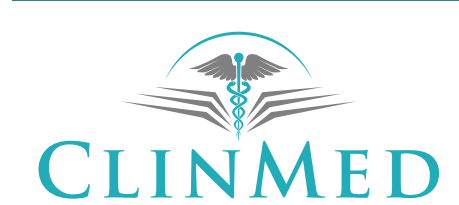

INTERNATIONAL LIBRARY

Citation: Darshan HS, Goswami SP (2020) Statistical Learning in Persons with Aphasia: A Critical Review of Literature. Int Arch Commun Disord 3:016. doi.org/10.23937/2643-4148/1710016 Accepted: October 24, 2020: Published: October 26, 2020

Copyright: (c) 2020 Darshan HS, et al. This is an open-access article distributed under the terms of the Creative Commons Attribution License, which permits unrestricted use, distribution, and reproduction in any medium, provided the original author and source are credited. 
be used in the article further. Tasks like Serial Reaction Time Task (SRTT), Dynamic systems control tasks [14], Artificial Grammar Learning (AGL), categorical learning, priming etc have been used in both general and aphasia research. Widely used tasks are SRTT and AGL, which are considered as paradigmatic methods to study statistical learning [15]. SRTT is the better measure of statistical learning [16]. The reasons to consider the fact that it is a better measure, learning in SRTT is more incidental than in AGL [17]; and in AGL, participants are informed about the presence of a structure, and they are asked to exploit it. SRTT is a well-established paradigm which does not require any linguistic processing, and moreover, participants with language impairments will not be precluded from their ability to complete the task.

In the standard form of SRTT, the target stimulus will appear in one of the possible locations on the display screen and corresponding key to the target location has to be pressed to give response. The target location will be in the form of rectangular or square boxes on the display screen and it is placed in the horizontal direction on the display screen (referred as horizontal variant). In another variant form, the target location can be static i.e., the stimulus will appear on the centre of the display (referred as central variant). In this central variant, where the stimuli (different colours- red, blue, green) appears at centre of the display screen, the sequence (example: red - blue -green - blue -red - green - blue - green - red) is corresponded to the response board having three or four keys with the mentioned colours. In the horizonal variant, where square boxes on the display screen are placed in horizontal direction. The deterministic (same sequence repeats after a certain number of trials) and probabilistic (some target location will be more probable than other, considering the previous locations) sequence types are used. Commonly used stimuli are asterisk, letter, words and pseudo words. The stimuli can be presented in the visual mode or in auditory mode. For example, in the auditory version, the phonemes/ words and the corresponding pictures for it will be displayed for a fixed duration. Participants need to identify the picture present on the display screen depicting each word/letter that was heard and press the key on the response pad.

In the implicit condition of SRTT, the participants are not informed about the sequence structure rather it will be unbeknownst to them and no instructions are given. But in the explicit form of SRTT, the instructions will be given to the participants that they need to learn the sequence and information regarding the sequence structure and length will also be given. Studies have tried to investigate the difference about the knowledge gained from learning in both the conditions [18-21]. Irrespective of the SRTT condition used, testing the knowledge gained from the learning has been studied using various procedures like free recall, generation of sequence pattern, answering the questions regarding the SRTT etc.
Extended learning time for the participants to check the performance and gain of knowledge. In addition, retention of knowledge is assessed after a few days of initial learning session [21-23].

It is well-known that PWA exhibits declarative memory or learning deficits. Alongside long-term memory, working memory is known to play a major role in learning and processing of information in day to today life. Explicit learning of sequence in SRTT is correlated to working memory $[24,25]$. Statistical learning would be an option for PWA, as they exhibit working memory deficits. Considerable research works have tried to assess whether statistical learning is spared or impaired in PWA. The goal of the paper is to critically review studies carried out using SRTT paradigm in PWA to discuss the learning differences in implicit and explicit condition, task designs, stimuli and participants characteristics.

\section{Search Method}

The following electronic bibliographic databases: MEDLINE, PsycINFO, Web of Science, ERIC ProQuest, PubMed and Google Scholar were searched for articles on statistical learning in aphasia. The search strategy combined keywords that relate to statistical learning and synonyms of statistical learning with terms that related to aphasia. An important criterion is that study should be carried out using SRTT and its variants (both visual and auditory forms). The search terms will be adapted for use with other bibliographic databases. The search was restricted to only English and there will be no publication year restrictions. The Boolean phrase used was 'aphasia or stroke and (statistical or procedural or implicit or sequential or SRTT)'. This search strategy resulted in 770 search results and specifically 117 article titles were related articles. Each title of the article was read carefully and if the word SRTT was found in the title, then the abstract was read further. Hand search of articles from the reference section of the included articles and in addition review studies in line with this topic were also screened. A total of 12 articles were found, one article was eliminated as it was a duplicate. With the consensus among the two authors, a total of 11 studies were finalized for further analyses.

\section{Analyses}

After reviewing the studies, methodological and study outcome differences across the studies were noticed. Inclusionary criteria for clinical group, task design and outcome measures varied across studies. These parameters were considered for discussing aphasia and statistical learning research which have used SRTT paradigm (Table 1).

\section{Neurotypical vs. Persons with Aphasia}

Among 11 articles reviewed, nine articles have studied the learning abilities both in the clinical group and Neuro-Typical Individuals (NTI) group. In all the nine 
Table 1: A summary of the methodology of the 11 studies.

\begin{tabular}{|c|c|c|c|c|c|c|}
\hline Study & $\begin{array}{l}\text { SRTT } \\
\text { version }\end{array}$ & Post-onset & SRTT form & $\begin{array}{l}\text { Explicit } \\
\text { learning }\end{array}$ & Explicit Knowledge & $\begin{array}{l}\text { Retention of } \\
\text { learning }\end{array}$ \\
\hline $\begin{array}{l}\text { Goschke, et al. } \\
\text { [26] }\end{array}$ & $\begin{array}{l}\text { Standard \& } \\
\text { Variant } \\
\text { (Auditory) }\end{array}$ & $\begin{array}{l}\text { Average } 3 \\
\text { months }\end{array}$ & Horizontal & No & Not measured & Not measured \\
\hline Boyd, et al. [27] & Standard & $\begin{array}{l}\text { Greater than } \\
6 \text { months }\end{array}$ & Central, colours & Yes & $\begin{array}{l}\text { Subjective awareness } \\
\text { and recognition }\end{array}$ & $\begin{array}{l}\text { Extended practice } \\
\text { of } 3 \text { days }\end{array}$ \\
\hline Boyd, et al. [18] & Standard & $\begin{array}{l}\text { At least } 6 \\
\text { months }\end{array}$ & Central, colours & Yes & $\begin{array}{l}\text { Subjective awareness, } \\
\text { recognition \& Recall } \\
\text { test }\end{array}$ & On day 3 \\
\hline Boyd, et al. [19] & Standard & $\begin{array}{l}\text { Greater than } \\
6 \text { months }\end{array}$ & Central, colours & Yes & $\begin{array}{l}\text { Subjective awareness } \\
\text { and recognition }\end{array}$ & On day 4 \\
\hline Boyd, et al. [20] & Standard & $\begin{array}{l}\text { Greater than } \\
6 \text { months }\end{array}$ & Central, colours & No & $\begin{array}{l}\text { Subjective awareness, } \\
\text { recognition \& Recall } \\
\text { test }\end{array}$ & Not measured \\
\hline Rosser, et al. [28] & Standard & $\begin{array}{l}\text { Average } 3 \\
\text { years }\end{array}$ & Horizontal & No & Not measured & Not measured \\
\hline Orrell, et al. [29] & Standard & $\begin{array}{l}\text { Greater than } \\
1 \text { year }\end{array}$ & Horizontal & No & Generation task & $\begin{array}{l}2 \text { weeks after day } \\
2 \text { (learning) }\end{array}$ \\
\hline $\begin{array}{l}\text { Schuchard \& } \\
\text { Thompson [30] }\end{array}$ & $\begin{array}{l}\text { Variant } \\
\text { (Auditory) }\end{array}$ & $\begin{array}{l}\text { Greater than } \\
1 \text { year }\end{array}$ & Horizontal & Yes & Prediction task & Not measured \\
\hline Dovern, et al. [21] & Standard & $\begin{array}{l}\text { Greater than } \\
4 \text { days }\end{array}$ & Horizontal & Yes & $\begin{array}{l}\text { Structured interview, } \\
\text { recall test }\end{array}$ & $\begin{array}{l}\text { After } 2 \text { days } \\
\text { of initial day of } \\
\text { learning }\end{array}$ \\
\hline $\begin{array}{l}\text { Schuchard, et al. } \\
\text { [31] }\end{array}$ & Standard & $\begin{array}{l}\text { Average } 6.8 \\
\text { years }\end{array}$ & Horizontal & No & Not measured & Not measured \\
\hline Dovern, et al. [32] & Standard & $\begin{array}{l}\text { Average } 4 \\
\text { months }\end{array}$ & Horizontal & No & Free recall & Not measured \\
\hline
\end{tabular}

studies, NTI has better performance than the PWA. Most of the studies have not explicitly mentioned the type of aphasia in the methodology and have not considered the different forms of aphasia. Among 11 studies, three studies $[26,30,31]$ have mentioned the type of aphasias included in the study. There is no significant difference in performance among the types of aphasia in the standard SRTT. But from the study [26], phonemic sequences were used as a stimulus in SRTT variant named Serial Search Task (SST) in Broca's aphasia. It was noted that persons with Broca's aphasia showed poorer performance in learning the phonemic sequences when compared to NTI. Persons with Broca's aphasia exhibited selective impairment in learning phonemic sequences when compared to other stimuli (non-linguistic stimuli in visuo-spatial domain). In the study [30], it was found that persons with Broca's (agrammatic) aphasia exhibited learning in SST. In this study, frequently occurring concrete words as a sequence was presented in auditory domain and corresponding visually images to those words. The use of different stimuli in both the studies could have led to the contrasting findings. The number of participants were less to have enough power to observe the learning in [26] study and also phone- mic sequence as a stimulus may not be a meaningful sequence to process. In addition, PWA have difficulty in phoneme discrimination [33,34], this might have been a contributing factor for impaired learning. Based on the findings, it is unsure to highlight the specific deficit in phonological processing in PWA. Future research can focus on using semantic and morpho-syntactic based stimuli to find the dissociation of impairment in procedural and declarative systems.

\section{Post-Onset of Stroke}

One of the inclusionary criteria of the clinical group to the experiment is post-onset of stroke based on the availability of the participants and objectives of the study. Among 11 articles, the highest post-onset time of stroke was six years and the least were within days of stroke during the acute phase. The average post-onset from the studies was around one year. Statistical learning is not dependent on post-onset of stroke. A study [32] found no correlation between post-onset of stroke and learning. Similarly, illness duration of patients with schizophrenia did not correlate with implicit learning [35]. 


\section{Age and Gender}

Age and Gender of PWA are also considered as factors of learning. From the 11 studies, the average age of the participants was 57.3 years. Older age of the participant was 81 years [27] and younger was 27 years [26]. It has been observed that age of the participants was not a barrier for learning. It was also found that there is no correlation between ages of the participants to general implicit learning [32]. Out of 11 studies, 10 studies have mentioned the number of male and female as PWA in the methodology. A total of 86 males and 52 females, showed no gender differences in learning. A study by [32] found no correlation between gender and learning abilities.

\section{Variants of SRTT}

SRTT variants like standard, auditory, AGL-SRTT variants etc have been used throughout the literature. Nine of the 11 studies have used the standard variant of SRTT. In this review, AGL paradigm and SRTT-AGL variant are not included. Equivocal results have been found on using standard SRTT i.e., PWA exhibits learning but not up to the level of NTI.

In the standard variant, non-linguistic shapes (like asterisk and other shapes), images of different colours are used as stimuli. The use of non-linguistic stimulus, due to the lack of meaningful features in the stimulus might create a difficulty in forming a representation and that leads to the added demands on processing. Studies using the standard variant have designed and used the paradigm in two ways. First, the sequence is mapped to the stimulus presentation (i.e., four squares displayed horizontally on the display screen where the stimulus will appear on one square at a time with the predefined sequence) and response key (mouse click or single response button on the keyboard). Second, the stimulus appears at the centre of the screen (with only one square) and response keys will be mapped with the features of the sequence (example, if green, yellow, blue and red are images appearing on the screen with a predefined sequence, then there will be four response buttons with the mentioned colours). In both designs i.e., central and horizontal, PWA have exhibited learning. Considering the motor abilities of PWA, touch screen mode can be used in future studies rather key presses or mouse clicks being more taxing for them. In addition, squares placed on the four quadrants of the display screen and stimulus appearing in a sequence which is called as spatial version could give a better picture of learning in visuo-spatial domain. The group differences in explicit knowledge observed in central version is of less importance compared to spatial version of SRTT [35].

Simultaneous presentation of linguistic stimuli (letters and words) in auditory and visual mode are used in some studies $[26,30]$. The association between auditory forms to visual can be meaningful but considering the working memory deficits in PWA, the added demands might be a contributing factor for inefficient learning of the unbeknownst sequence. PWA has exhibited learning but not to the level of NTI. Further investigations can consider the presentation of stimuli in only one mode, which can be explored whether PWA shows better learning compared to the earlier methodologies.

\section{Implicit vs. Explicit}

SRTT studies have been carried out using various methodological designs in implicit condition. Learning in implicit condition does not fetch awareness and knowledge about the learnt information but PWA has shown learning of sequences. Patients with Schizophrenia, Dementia, and Mild Cognitive Impairment have intact implicit learning though they exhibit working memory deficits.

Only five out of eleven studies have investigated learning both in explicit and implicit condition. NTI exhibited significant learning in explicit condition when compared to implicit condition. Compared to NTI, PWA showed impaired learning in explicit condition, even after getting information regarding the sequence structure prior to the task. Explicit instructions and overt strategy to learn might place demands on working memory that might be cumbersome for persons with stroke. Though PWA exhibit working memory deficits, they showed learning in implicit condition but not in explicit condition. Explicit learning is correlated to working memory $[24,25]$.

While investigating learning in explicit condition, the researchers have carried out the task first in implicit condition and followed in the explicit condition in PWA. It was not counterbalanced because providing information of the existence of a sequence and pattern of sequence in the explicit condition would prevent subsequent learning in implicit condition. Even though the product of learning from implicit condition is not expressible, the effect of performing tasks might influence the learning in explicit condition. Further investigations should study only in explicit condition by not introducing the implicit condition in the methodology.

\section{Declarative Knowledge}

Apart from the outcome measures derived from the task, the explicit knowledge is also assessed. The knowledge gained from SRTT learning in explicit condition is called explicit knowledge. Eight of the eleven studies measured the explicit knowledge gained from learning using various procedures like subjective awareness from questionnaire, recognition/prediction, and Recall and generation test. Some studies which have carried out learning only in implicit condition has also assessed the knowledge $[20,29,32]$. PWA demonstrated knowledge which is reflected through the scores achieved from the tasks administered, scores are better in explic- 
it condition than implicit condition and but poorer than NTI. Generation task i.e., generating the sequence within the paradigm can be utilized in the future studies.

\section{Retention}

Five of the eleven studies assessed the retention of learning in PWA. Assessment of retention carried out after the post learning session varied from the first day to two weeks. PWA demonstrates retention of learning but not up to the level of NTI. Benefit of explicit instructions on retention of learnt information is better when compared to implicit condition of learning both in PWA and NTI. The retention of learning is dependent on various factors like interval between learning session to retention, sleep, activities that are carried out between learning and retention session, intake of medicines in persons with stroke and stimulus features. Particularly learning in implicit condition, the interval between learning session and retention session can be placed shorter to 12 -hour, 24-hour, $2^{\text {nd }}$ day and week after. This might give more information about the optimal performance in PWA. Future research needs to control these aspects while studying retention of learning while using SRTT and its variants in PWA [36].

\section{Conclusion}

The goal of the paper was to critically evaluate the parameters which revolve around the statistical learning from SRTT in implicit and explicit condition in PWA. Significant methodological differences are present in the studies that are reviewed. Investigating learning in explicit condition, number of elements in the sequence and the type of sequence (deterministic vs. probabilistic), use of response mode and maintaining the interval from learning session to retention session should be considered to find the differences in learning from SRTT paradigm. Further, this type of learning can be correlated with language competence in future research. This review has highlighted the possible methodological differences and also suggested the future directions for statistical learning research using SRTT and its variants in PWA.

\section{Acknowledgements}

The authors are thankful to the Director, All India Institute of Speech and Hearing, Mysuru, for the permission and support to carry out the research at the institute.

\section{Conflict of Interest}

There are no conflicts of interest.

\section{Funding Sources}

The authors have no funding sources to declare.

\section{Authors Contribution}

Darshan HS: Drafting and editing the manuscript.
Goswami SP: Supervision, Editing the manuscript, Manuscript proofreading.

\section{References}

1. Lieberman DA (2012) Human learning and memory. Cambridge University Press.

2. Ullman M (2001) A neurocognitive perspective on language: The declarative/procedural model. Nature Reviews Neuroscience 2: 717-726.

3. Ullman M (2004) Contributions of memory circuits to language: The declarative/procedural model. Cognition 92: 231-270.

4. Ullman MT, Corkin S, Coppola M, Hickok G, Growdon $\mathrm{JH}$, et al. (1997) A neural dissociation within language: Evidence that the mental dictionary is part of declarative memory, and that grammatical rules are processed by the procedural system. Journal of Cognitive Neuroscience 9: 266-276.

5. Quam C, Wang A, Maddox WT, Golisch K, Lotto A (2018) Procedural-Memory, Working-Memory, and Declarative-Memory Skills Are Each Associated with Dimensional Integration in Sound-Category Learning. Frontiers in Psychology 9: 1828.

6. Breitenstein C, Kamping S, Jansen A, Schomacher M, Knecht S (2004) Word learning can be achieved without feedback: Implications for aphasia therapy. Restorative Neurology and Neuroscience 22: 445-458.

7. Hsu HJ, Bishop DV (2014) Sequence-specific procedural learning deficits in children with specific language nimpairment. Developmental Science 17: 352-365.

8. West G, Vadillo MA, Shanks DR, Hulme C (2018) The procedural learning deficit hypothesis of language learning disorders: we see some problems. Developmental Science 21: e12552.

9. McNeil MR (1983) Aphasia: Neurological considerations. Topics in Language Disorders 3: 1-20.

10. LaPointe LL (2005) Aphasia and related neurogenic language disorders. Thieme Medical Pub.

11. Chertkow H, Bub D, Deaudon C, Whitehead V (1997) On the status of object concepts in aphasia. Brain and language 58: 203-232.

12. Berthier ML (2001) Unexpected brain-language relationships in aphasia: Evidence from transcortical sensory aphasia associated with frontal lobe lesions. Aphasiology 15: 99-130.

13. Conway CM, Christiansen $\mathrm{MH}$ (2005) Modality-constrained statistical learning of tactile, visual and auditory sequences. Journal of Experimental Psychology: Learning, Memory, and Cognition 31: 24-39.

14. Berry DC, Broadbent DE (1984) On the relationship between task performance and associated verbalizable knowledge. The Quarterly Journal of Experimental Psychology Section A 36: 209-231.

15. Shanks DR, Rowland LA, Ranger MS (2005) Attentional load and implicit sequence learning. Psychological Research 69: 369-382.

16. Destrebecqz A, Cleeremans A (2001) Can sequence learning be implicit? New evidence with the Process Dissociation Procedure. Psychonomic Bulletin \& Review 8: 343-350.

17. Pretz JE, Totz KS, Kaufman SB (2010) The effects of mood, cognitive style, and cognitive ability on implicit learning. Learning and Individual Differences 20: 215-219. 
18. Boyd LA, Winstein CJ (2003) Impact of explicit information on implicit motor-sequence learning following middle cerebral artery stroke. Physical Therapy 83: 976-989.

19. Boyd LA, Winstein CJ (2006) Explicit information interferes with implicit motor learning of both continuous and discrete movement tasks after stroke. Journal of Neurologic Physical Therapy 30: 46-57.

20. Boyd LA, Quaney BM, Pohl PS, Winstein CJ (2007) Learning implicitly: Effects of task and severity after stroke. Neurorehabilitation and Neural Repair 21: 444-454.

21. Dovern A, Fink GR, Timpert DC, Saliger J, Karbe $H$, et al. (2016) Timing matters? Learning of complex spatiotemporal sequences in left-hemisphere stroke patients. Journal of Cognitive Neuroscience 28: 223-236.

22. Nemeth D, Janacsek K (2011) The dynamics of implicit skill consolidation in young and elderly adults. Journals of Gerontology Series B: Psychological Sciences and Social Sciences 66: 15-22.

23. Hedenius M, Persson J, Tremblay A, Adi-Japha E, Veríssimo J, et al. (2011) Grammar predicts procedural learning and consolidation deficits in children with specific language impairment. Research in Developmental Disabilities 32: 2362-2375.

24. Kaufman SB, DeYoung CG, Gray JR, Jiménez L, Brown J, et al. (2010) Implicit learning as an ability. Cognition 116: 321-340.

25. Unsworth N, Engle RW (2005) Individual differences in working memory capacity and learning: Evidence from the serial reaction time task. Memory \& Cognition 33: 213-220.

26. Goschke T, Friederici AD, Kotz SA, Van Kampen A (2001) Procedural learning in Broca's aphasia: Dissociation between the implicit acquisition of spatio-motor and phoneme sequences. Journal of Cognitive Neuroscience 13: 70-388.
27. Boyd LA, Winstein CJ (2001) Implicit motor-sequence learning in humans following unilateral stroke: The impact of practice and explicit knowledge. Neuroscience Letters 298: 65-69.

28. Rosser N, Heuschmann P, Wersching H, Breitenstein C, Knecht S, et al. (2008) Levodopa improves procedural motor learning in chronic stroke patients. Archives of Physical Medicine and Rehabilitation 89: 1633-1641.

29. Orrell AJ, Eves FF, Masters RSW, MacMahon KMM (2007) Implicit sequence learning processes after unilateral stroke. Neuropsychological Rehabilitation 17: 335-354.

30. Schuchard J, Thompson CK (2014) Implicit and explicit learning in individuals with agrammatic aphasia. Journal of Psycholinguistic Research 43: 209-224.

31. Schuchard J, Nerantzini M, Thompson CK (2017) Implicit learning and implicit treatment outcomes in individuals with aphasia. Aphasiology 31: 25-48.

32. Dovern A, Niessen E, Ant JM, Saliger J, Karbe H, et al. (2017) Timing independent spatial motor sequence learning is preserved in left hemisphere stroke. Neuropsychologia 106: 322-327.

33. Oscar-Berman M, Zurif EB, Blumstein S (1975) Effects of unilateral brain damage on the processing of speech sounds. Brain and Language 2: 345-355.

34. Miceli G, Caltagirone C, Gainotti G, Payer-Rigo P (1978) Discrimination of voice versus place contrasts in aphasia. Brain and Language 6: 47-51.

35. Remillard G (2014) The study of sequence learning in individuals with schizophrenia: a critical review of the literature. Journal of Neuropsychology 8: 231-245.

36. Heilman KM, Bowers D, Valenstein E (1993) Emotional disorders associated with neurological diseases. Clinical Neuropsychology 3: 461-497. 